\title{
ASSOCIAÇÕES DE PAIS E PARTICIPAÇÃO COLETIVA: OPORTUNIDADE PERDIDA?
}

\author{
Maria Martins ${ }^{1}$ \\ Teresa Sarmento ${ }^{2}$
}

Resumo: Da complexidade que caracteriza a educação, em termos de práticas e objetivos, decorre a pluralidade de perceções, sentidos e procedimentos, quer a nível individual, quer coletivo e institucional. Nesse sentido, e como bem sublinha Silva (1994:308) qualquer reflexão sobre a problemática da relação escola-família representará sempre a ponta de um enorme icebergue.

Com efeito, para além do que visivelmente as escolas exigem aos pais e que resulta da produção normativa, outros fatores será necessário analisar para uma melhor caracterização desta problemática. Incluem-se nessa lista aspetos ainda pouco estudados, entre os quais se destaca a forma como as famílias se organizam e posicionam face a essa situação e o papel desempenhado pelas Associações de Pais (APs) na construção de soluções que contribuam para um maior e melhor envolvimento das famílias na vida escolar dos seus educandos.

Neste artigo damos conta dos resultados de uma parte de um estudo realizado no âmbito da tese de doutoramento3, no que respeita à participação parental através da AP. Os dados, obtidos por aplicação de inquérito por questionário e entrevista a pais/encarregados de educação e professores com funções de direção de turma, revelam uma perceção muito positiva sobre a importância destas associações, deixando igualmente clara a preocupação dos inquiridos relativamente às dificuldades de funcionamento das mesmas e à oportunidade (perdida!?) que tal representa em termos de construção de uma participação parental coletiva $e$, consequentemente, mais eficaz do ponto de vista do seu contributo na construção de soluções positivas para a edificação da relação escolafamília-comunidade e a melhoria da sua ação coeducativa.

\footnotetext{
${ }^{1}$ Docente do Agrupamento de Escolas Viseu Sul (mariamartinssousa@gmail.com ).

${ }^{2}$ Professora Auxiliar da Universidade do Minho (tsarmento@ie.uminho.pt ).

${ }^{3}$ Realizada na Universidade de Granada e orientada por: Teresa Sarmento (Professora da Universidade do Minho), Juán Antonio Lopéz Nuñez e Juán Manuel Trujillo Torres (Professores da Universidade de Granada)
} 
Palavras-chave: Associativismo de Pais, Participação Coletiva, Cidadania

\begin{abstract}
The plurality of perceptions, meanings and practices not only at the individual level but also at the collective and institutional level is the result of the complexity that characterizes education in terms of practices and objectives. Accordingly, and as Pedro Silva (1994:308) emphasizes, any approach to the school/family relationship issue will always be just the tip of an enormous iceberg.

Indeed, in addition to what schools visibly demand from the parents which results from the normative production, it is necessary to consider some other factors for a better characterization of this problem. This list includes some aspects that are not quite well studied yet, among which stands out the way families are organized and positioned to face the situation and the role played by the Parents Associations in the building up of solutions which contribute to a bigger and better involvement of the families in their children's school life.

In this article we report the results of a study we've done for the Doctoral Thesis4, concerning the parental participation within the Parents Association.

The results obtained by applying a questionnaire and an interview with parents and teachers as class directors show a very positive perception about the importance of these associations, but they reveal clearly the worry of the inquired people with their operating difficulties and the (lost?) opportunity that it represents in terms of the construction of a collective parental participation and, consequently, more efficient from the point of view of their contribution to the edification of positive solutions to the construction of the school/family relationship and to the improvement of its coeducational action.
\end{abstract}

Key words: Parents Association; Colective Participation; Citizenship.

\title{
1. ENQUADRAMENTO TEÓRICO E DELIMITAÇÃO DO PROBLEMA
}

A atividade educativa constitui uma realidade altamente complexa que lhe advém, por um lado, do facto de se situar no âmbito das relações interpessoais, mas igualmente do carácter difuso dos seus objetivos, tanto quanto do seu carácter eminentemente social evidenciado pela existência de vários atores sociais envolvidos na responsabilidade da sua concretização, entre outros. Potenciado pela crescente exigência da

\footnotetext{
${ }^{4}$ Thesis done at the University of Granada and supervised by Teresa Sarmento (Professor at the University of Minho), Juán Antonio Lopez Nuñez e Juán Manuel Trujillo Torres ( Professors at the University of Granada).
} 
sociedade das últimas décadas, designadamente em termos de otimização dos resultados, o escrutínio permanente a que a escola está sujeita tem aumentado a pressão no sentido de uma ação partilhada e desejavelmente concertada entre todos os agentes educativos, sejam eles professores, pais ou outros. Inscreve-se nessa perspetiva a valorização do incremento da participação, envolvimento e implicação das comunidades, de modo particular das famílias, no percurso escolar dos seus educandos.

A premência da aproximação dos pais/encarregados de educação à escola, trazendo-os a participar ativamente, quer no desenvolvimento de atividades educativas, quer na partilha de responsabilidades na tomada de decisões fundamentais sobre e para a vida escolar, tem conhecido expressão significativa nos estudos publicados, nos meios de comunicação social que a têm trazido para a esfera pública e, sobretudo, em sede de produção normativa que, embora com avanços e recuos, tem sublinhado a necessidade dessa corresponsabilização, através de um longo percurso de ascendência legislativa no que concerne à sua legitimação e operacionalização. Deste modo, tal como referem Sarmento, T. (2009a) ou Lima e Sá (2002), o envolvimento da família na educação escolar, para além de um direito e de um valor, passa formalmente a constituir também uma responsabilidade e um dever.

As dinâmicas sociais, caracterizadas por mudanças permanentes e aceleradas, o aumento da importância atribuída à educação e à formação das crianças e jovens, bem como uma consciência crescente da importância da colaboração entre a escola e a família no seu sucesso escolar e educativo, levam a que, várias décadas passadas sobre a primeira referência normativa à relação escola-família, através da Lei $\mathrm{n}^{\circ}$ $7 / 77^{6}$, se apresente hoje cada vez mais necessária uma intervenção educativa assente numa dinâmica de participação, colaboração e corresponsabilização entre as várias instâncias educativas em que a criança vivencia experiências e se desenvolve.

Assim, a escola que, reclamando a participação parental, tem revelado, paradoxalmente, dificuldades na adaptação a essas mudanças da sociedade, depara-se hoje com a necessidade e responsabilidade da implementação e desenvolvimento de estratégias de aproximação das famílias, chamando-as a colaborar na hercúlea missão escolar, o que se torna mais difícil numa sociedade cada vez mais heterogénea. A diversidade de modelos familiares, por exemplo, tem grande influência na

\footnotetext{
5 No presente artigo utilizamos indiferenciadamente a designação de pais e de encarregados de educação, sabendo que nos referimos ao adulto que assume a responsabilidade pelo acompanhamento escolar da criança enquanto aluno.

${ }^{6}$ A Lei $n^{\circ} 7 / 77$ constitui o primeiro documento legislativo sobre o associativismo parental.
} 
forma como se realiza o seu relacionamento com a escola, cabendo a esta estar atenta e ter em consideração a heterogeneidade e as especificidades de cada família, para melhor planificar a sua ação escolar e educativa e a construção de modelos de participação parental.

Entre as formas e possibilidades de intervenção dos pais/encarregados de educação na vida das escolas, a AP representa um espaço privilegiado de construção e planeamento dessa intervenção colaborativa, desejavelmente de todos os pais/encarregados de educação. Ao proporcionar uma base alargada de participação parental, a AP pode dar um contributo decisivo no sentido de esbater a clivagem sociológica (Silva, 2002: 104; 2003: 212) de que enferma a relação escola-família, com especialíssimo significado e acuidade no caso das famílias que se encontram em descontinuidade e até rutura cultural com a instituição escolar e que dela se sentem e vivem mais afastadas.

Neste sentido, consideramos fundamental que a escola contribua, em primeiro lugar, para a formação da $\mathrm{AP}$ e que, em permanência, facilite a sua ação e acolha de forma positiva e construtiva as suas intervenções e contributos. Assim, ao descentralizar-se e aproximar-se dos outros atores, a escola melhorará, seguramente, os padrões de qualidade educativa, tal como lembra Sousa (1998).

Miguéns (2005) acrescenta que a escola, ao potenciar o envolvimento de todas as famílias, não só leva a que os pais participem ativamente na educação dos seus filhos, como se transforma num espaço de aprendizagem dos próprios, o que lhes proporciona, por sua vez, escolhas mais informadas sobre trajetos educativos em relação aos seus educandos.

Por outro lado, o estreitamento das relações entre escola, família e comunidade, ao implicar uma atitude de comunicação e participação dos vários atores, induz, segundo Silva (2003), a uma cultura de cidadania e a um aprofundamento democrático, quer a nível representativo quer participativo.

$\mathrm{Na}$ mesma linha de pensamento, Sarmento, T. (2009c) considera que a escola, entendida como espaço de vida e agência de desenvolvimento das comunidades, representa um contexto privilegiado para o exercício do direito e dever de cidadania. Em continuidade de reflexão dizíamos que é nesse quadro que deve ser feita a reflexão em torno da relação escolafamília-infância-comunidade. Desta forma, estas ligações, enquanto janelas para a construção de uma sociedade que garanta o espaço e dê voz a todos os seus cidadãos, consubstanciam o desenvolvimento e a existência de "comunidades cidadãs", capazes de acolher, respeitar e valorizar a sua realidade multicultural, bem como uma "escola cidadã, que promova a construção da cidadania de todos os que nela vivem ou com ela se relacionam (ibid: 51-54) 
Silva (2003: 355), alertando para o papel mobilizador que a escola pode desempenhar nas comunidades, enquanto agência de desenvolvimento das mesmas, sublinha as vantagens deste envolvimento dos pais na vida escolar dos seus filhos, designadamente através das APs e aponta o facto de toda essa prática consubstanciar um aumento da democratização da escola e da comunidade envolvente.

Bronfenbrenner (1996), no âmbito da sua perspetiva ecológica do desenvolvimento humano, em que concebe como fundamental o equacionamento de todas as instâncias nas quais a criança vivencia experiências, defende que a existência e a qualidade da relação estabelecida entre a escola e a família poderá ter tanta influência na capacidade de aprendizagem da criança como as formas e métodos de ensino aplicados nos processos de ensino-aprendizagem. Nesse sentido, sublinha a importância vital que tem o desenvolvimento de interações positivas e concertadas entre todos esses contextos educativos.

Esta concertação pode ser potenciada em contexto associativo. Dando voz às famílias através dos encarregados de educação, torna-se possível uma apreensão mais completa e, consequentemente, mais fiel da realidade escolar. Esta visão abrangente e participada no coletivo, ao proporcionar um conhecimento holístico da realidade em termos de necessidades e potencialidades, permite a construção de modelos de participação parental mais adequados e mais sustentados. Numa macro análise de estudos realizados no âmbito de cursos de estudos superiores especializados (Sarmento, T., 2006d), apontamos já como principais as seguintes conclusões: a) nos últimos anos aumentou o número de APs; b) quando se fala em dinamismo de uma AP, está-se a referir essencialmente ao trabalho desenvolvido pelo grupo restrito que integram os órgãos sociais das mesmas; c) maioritariamente, os pais que fazem parte das direções associativas são os que detêm a mesma linguagem que os professores; d) mesmo quando não estão agrupados em associações, os pais mobilizamse quando consideram que os seus filhos estão face a um problema comum.

Tendo em atenção as linhas teóricas acima referenciadas, num trabalho conjunto de investigadoras focalizadas nesta área de saber, de seguida apresentamos os resultados de um estudo referentes ao tópico do associativismo parental, realizado no âmbito de uma tese de doutoramento, cujo objetivo fundamental era a caracterização da participação das famílias nas escolas dos $2^{\circ}$ e $3^{\circ}$ ciclos do ensino básico de um distrito da zona centro do pais, através de três canais: Diretor de Turma (DT), Aluno e AP.

O estudo parcelar aqui apresentado analisa a perceção dos encarregados de educação e dos DTs relativamente ao papel e 
funcionamento da AP na construção da relação escola-famíliacomunidade.

\section{METODOLOGIA}

\subsection{Recolha de dados: procedimentos}

Por se tratar da análise de fenómenos sociais complexos que se pretendem descrever e cujos resultados se pretendem generalizar à população alvo, considerámos importante não só incluir dois grupos de atores como acima referido, mas dentro de cada grupo inquirir um número significativo de sujeitos. Nessa perspetiva, foi nossa opção desenvolver uma abordagem qualitativa cruzada com recursos quantitativos utilizando como principal instrumento de recolha de dados um inquérito por questionário aos elementos dos dois subgrupos da população.

Dos 2089 questionários enviados aos encarregados de educação (amostra aceitante, entre os 3268 que constituíam a população) foram recolhidos 1219, correspondendo a $37,3 \%$ da respetiva população. Em relação aos questionários aplicados aos DTs, dos 163 entregues ao total da população, foram devolvidos 112 , perfazendo uma taxa de $68,71 \%$.

Os questionários aplicados são constituídos maioritariamente por questões semifechadas e um número reduzido de questões abertas, divididas em blocos: Variáveis de caracterização sociodemográfica; Comunicação dos encarregados de educação com o DT de turma e Envolvimento dos encarregados de educação na vida escolar.

Com o objetivo de obter informação mais aprofundada, e consubstanciando uma abordagem qualitativa, foram realizadas entrevistas a alguns elementos de cada um dos subgrupos constituintes da amostra -7 encarregados de educação e 4 DTs. No que respeita aos DTs, prevaleceu como critério de seleção a experiência profissional, e nos encarregados de educação tentou-se criar uma amostra o mais abrangente possível em termos de idade, estado civil, grau de parentesco com o aluno e formação académica, para além de se integrarem elementos de todas as escolas do Agrupamento de modo que a população estivesse o mais bem representada possível.

\subsection{Caracterização sociodemográfica dos subgrupos inquiridos}

No grupo dos encarregados de educação, a idade varia entre um mínimo de 18 e um máximo de 77 anos, apresentando um valor médio de 41 anos. Pode verificar-se que a classe etária mais representada é 36-40 
anos que apresenta $31 \%$ dos casos, seguindo-se a classe de $41-45$ anos com 29\%. As idades extremas (até 30 anos e mais de 55 anos) são as menos representadas, com $2 \%$ cada.

Verifica-se, ainda, que a grande maioria da amostra (85\%) é do sexo feminino e é casado ou vive em união de facto (86\%). A percentagem de encarregados de educação divorciados ou separados é de $9 \%$.

A quase totalidade dos inquiridos são pai ou mãe (95\%). Daqui se pode depreender que, sendo a maioria do sexo feminino, a maior parte dos encarregados de educação são mães, o que corresponde a uma realidade comum em Portugal, segundo os estudos publicados e referidos, uma vez que são maioritariamente as mães que assumem o papel de educadoras dos filhos. Consideramos importante registar o facto de $2 \%$ dos encarregados de educação serem tia, amiga, companheira e amiga, cunhada, madrinha, padrasto, padrinho, prima, sobrinho, tio e tio avô, o que pode corresponder a situações de ausência dos pais por emigração, ou outras geradas por outras situações.

As habilitações mais observadas são o $2^{\circ}$ ciclo do ensino básico, com $26 \%$, o ensino secundário, com $23 \%$ e o $3^{\circ}$ ciclo, com $20 \%$. As habilitações extremas (primeiro ciclo do ensino básico e ensino superior) são as menos representativas, com $15 \%$ cada e apenas $1 \%$ dos encarregados de educação tem formação superior ao nível de pósgraduações, mestrado ou doutoramento.

Relativamente à profissão exercida atualmente pelos encarregados de educação, verifica-se uma grande heterogeneidade. Por essa razão, optámos por não fazer associações de profissões, nomeadamente através da classificação nacional, por considerarmos que se poderiam perder algumas especificidades importantes. Assim, destaca-se em primeiro lugar o grupo de domésticas, com 20,2\%, as profissões ligadas ao comércio com 10,8\%, o grupo de desempregados com 9,6\%, a profissão de professor, com $7 \%$ dos casos, assistente operacional com 6,3\%, seguida de empresários e empregado fabril com 3,9\% cada, funcionário público com $3,4 \%$ e empregadas de limpeza com $3,2 \%$.

$\mathrm{Na}$ amostra de DTs, a idade apresenta um valor médio de 45,02 anos, com uma dispersão de valores de $17 \%$, sendo os valores mínimo e máximo, respetivamente, 27 e 57 anos. As classes etárias mais representadas são $41-45$ anos e mais de 50 anos com $27 \%$ cada, seguidas da classe 46-50 anos, com 20\%, até 35 anos com 16\%, e 36-40 anos com $10 \%$. À semelhança do verificado entre os encarregados de educação, a grande maioria dos DTs é do sexo feminino (79\%).

Os DTs têm, em média, 21 anos de experiência profissional, variando esse valor entre 3 e 36 anos de serviço docente. A maioria tem entre 11 e 25 anos de serviço (56\%), sendo uma minoria os que têm menos de 10 
anos de experiência profissional (10\%). A grande maioria pertence aos quadros (89\%), o que perfaz uma situação profissional docente estável.

\section{ALGUNS RESULTADOS DO ESTUDO: ANÁLISE REFLEXIVA E CONTEXTUALIZADA}

Feita a caraterização sumária da amostra, iniciamos agora a análise sobre as representações de pais sobre os níveis e contextos de comunicação e de participação entre escola e famílias através da AP.

\subsection{Nível e contextos de comunicação/participação escola-família através da AP}

Perceção dos encarregados de educação

\section{Quadro I}

Importância atribuída à AP

\begin{tabular}{lrr}
\hline & Frequência & Percentagem \\
\hline Não & 111 & 9,4 \\
Sim & 1074 & 90,6 \\
Não respondeu & 34 & 2,8 \\
\hline Total & 1219 & 100,0 \\
\hline
\end{tabular}

A observação do quadro I permite-nos verificar que a grande maioria dos encarregados de educação ( $91 \%$ dos que responderam à questão) considera importante a existência da AP. De salientar que cerca de 2,8\% dos inquiridos não respondeu a esta questão.

\section{Quadro II}

Encarregados de educação que fazem parte da AP

\begin{tabular}{lrr}
\hline & Frequência & Percentagem \\
\hline Não & 1011 & 86,6 \\
Sim & 157 & 13,4 \\
\hline Total & 1168 & 100,0 \\
\hline
\end{tabular}

No quadro II pode observar-se que, entre os encarregados de educação que responderam a esta questão, a grande maioria (87\%) não é membro da AP, verificando-se que $1,1 \%$ afirmou não existir essa associação e $3,0 \%$ não deu qualquer resposta. 


\section{Gráfico I}

Frequência de participação nas reuniões da AP

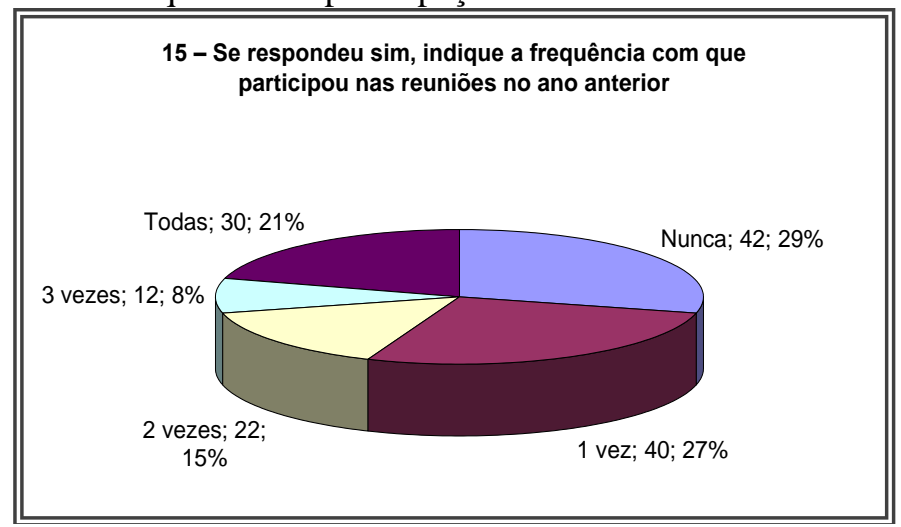

A análise do gráfico I permite-nos constatar que, entre os 157 encarregados de educação que dizem fazer parte da AP da escola do seu educando, respondendo sim à questão anterior, e em relação à frequência com que vão às reuniões, a situação mais verificada é "nunca", assinalada por $29 \%$ dos elementos, seguindo-se o grupo dos que vão 1 vez por ano e que são $27 \%$ dos casos e os que dizem ir a todas as reuniões (21\%). Na amostra, há $15 \%$ que vão 2 vezes por ano e $8 \%$ respondem que vão 3 vezes, tendo sido 9 os que não deram qualquer resposta a esta questão.

\section{Gráfico II}

A AP como intermediária no tratamento de assuntos na escola

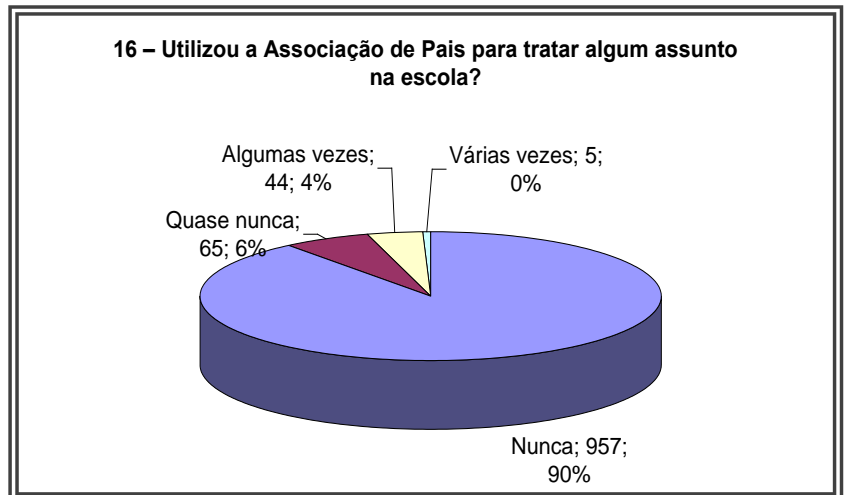

Ao observar os dados do gráfico II, constatamos que a esmagadora maioria dos encarregados de educação $(90 \%)$ nunca utiliza a AP para tratar qualquer assunto na escola, $6 \%$ respondem quase nunca o fazerem e 
4\% fazem-no algumas vezes. De sublinhar as 148 não respostas, que correspondem a $12,1 \%$ da amostra.

\section{Quadro III}

Assuntos da escola tratados através da AP

\begin{tabular}{|c|c|c|c|c|}
\hline & \multicolumn{2}{|c|}{$\begin{array}{c}\text { Não } \\
\text { assinalado }\end{array}$} & \multicolumn{2}{|c|}{ Assinalado } \\
\hline & $\mathrm{N}$ & $\%$ & $\mathrm{~N}$ & $\%$ \\
\hline $\begin{array}{l}17.1 \text { Assuntos relacionados com o } \\
\text { aproveitamento/comportamento do seu educando }\end{array}$ & 92 & 80,7 & 22 & 19,3 \\
\hline 17.2 Apresentar sugestões para o funcionamento da escola & 72 & 63,2 & 42 & 36,8 \\
\hline $\begin{array}{l}\text { 17.3 Pedir esclarecimentos relativamente ao funcionamento } \\
\text { da escola }\end{array}$ & 94 & 82,5 & 20 & 17,5 \\
\hline $\begin{array}{l}\text { 17.4 Pedir ajuda na colaboração a dar ao seu educando em } \\
\text { casa }\end{array}$ & 109 & 95,6 & 5 & 4,4 \\
\hline $\begin{array}{l}\text { 17.5 Apresentar queixa relativamente ao trabalho dos } \\
\text { professores do seu educando }\end{array}$ & 111 & 97,4 & 3 & 2,6 \\
\hline $\begin{array}{l}\text { 17.6 Manifestar desagrado sobre o comportamento dos } \\
\text { funcionários com os alunos }\end{array}$ & 107 & 93,9 & 7 & 6,1 \\
\hline $\begin{array}{l}17.7 \text { Pedir informações sobre as decisões tomadas pelos } \\
\text { representantes dos pais nos órgãos de gestão da escola }\end{array}$ & 86 & 75,4 & 28 & 24,6 \\
\hline $\begin{array}{l}\text { 17.8 Pedir ajuda na resolução de questões administrativas } \\
\text { (papéis e documentos) }\end{array}$ & 111 & 97,4 & 3 & 2,6 \\
\hline 17.9 Outros. (Quais?) & 104 & 91,2 & 10 & 8,8 \\
\hline
\end{tabular}

Uma análise aos dados apresentados pelo quadro III permite-nos afirmar que, entre os $10 \%$ dos encarregados de educação que tratam assuntos da escola utilizando a AP como veículo intermediário, $37 \%$ o faz quando pretende "Apresentar sugestões para o funcionamento da escola", $25 \%$ diz fazê-lo para "Pedir informações sobre as decisões tomadas pelos representantes dos pais nos órgãos de gestão da escola", 19\% para tratar de "Assuntos relacionados com o aproveitamento/comportamento do seu educando" e $18 \%$ para "Pedir esclarecimentos relativamente ao funcionamento da escola".

Em síntese, podemos verificar que para os encarregados de educação a importância da AP é indiscutível, pois a quase totalidade lhe reconhece importância ou muita importância.

No entanto, e paradoxalmente, no que respeita à concretização pessoal dessa importância atribuída, através da sua participação enquanto membro ativo, a maior parte declina essa responsabilidade, uma vez que apenas uma minoria faz parte dessa instância, sendo entre estes, uma minoria ainda mais reduzida os que participam nas reuniões e, consequentemente, na construção de uma intervenção capaz de dar um contributo positivo e assertivo na busca de respostas às problemáticas do dia a dia da vida escolar. Este parece ser um dos grandes obstáculos à 
participação coletiva dos pais e encarregados de educação na vida da escola.

Como resultado deste afastamento, a AP raramente é reconhecida como meio de comunicação e participação na escola. Deste modo, a conclusão mais imediata a tirar é que, efetivamente, as APs correspondem a um espaço de atuação dos pais que não tem sido aproveitado, continuando a ter, por falta de adesão, um papel marginal, contrariamente ao objetivo com que foram criadas.

Poderíamos dizer que é um potencial interventivo dos pais que continua desativado na maioria dos casos, em favor da prevalência da tradicional participação individual que, sendo importante e muitas vezes indispensável e insubstituível, resulta bem menos eficaz no que toca a uma intervenção coletiva e transformadora da escola.

Com efeito, a AP representa uma oportunidade de os encarregados de educação construírem e desenvolverem uma participação estruturada, mais esclarecida e mais eficaz no sentido de se fazerem ouvir e de defenderem os seus interesses. Enquanto entidade coletiva e legalmente constituída o seu poder de intervenção é mais claro e os seus direitos de cidadania mais facilmente percetíveis.

Analisadas as perceções dos pais, importa agora atender às representações dos DTs sobre a relevância dos papéis assumidos na escola pela AP.

\subsection{Perceção dos DTs}

\section{Quadro IV}

Importância atribuída à AP

\begin{tabular}{lrr}
\hline & Frequência & Percentagem \\
\hline Muito importante & 19 & 25,7 \\
Importante & 33 & 44,6 \\
Pouco importante & 22 & 29,7 \\
\hline Total & 74 & 100,0 \\
\hline
\end{tabular}

A análise ao quadro IV permite-nos verificar que, entre os 74 DTs que se pronunciaram sobre a importância da AP, $70 \%$ considera que a mesma é importante ou muito importante, enquanto que $30 \%$ lhe atribui pouca importância. Em 8,6\% dos casos é afirmado que essa associação não existe. Verificando-se 31 não respostas à questão, o que pode traduzir o desconhecimento dos DTs sobre a sua realidade escolar no que respeita à atividade associativa parental ou, em contramão, a baixa atividade destas associações tornando-as invisíveis. .

Os elementos que consideram que a AP é importante ou muito importante, apresentam como justificação para esse reconhecimento as razões que se seguem no quadro $\mathrm{V}$. 


\section{Quadro V}

Razões da importância ou muita importância da AP

\begin{tabular}{|c|c|c|c|c|}
\hline & \multicolumn{2}{|c|}{$\begin{array}{c}\text { Não } \\
\text { assinalado }\end{array}$} & \multicolumn{2}{|c|}{ Assinalado } \\
\hline & $\mathrm{N}$ & $\%$ & $\mathrm{~N}$ & $\%$ \\
\hline $\begin{array}{l}\text { 10.1 A AP desempenha um papel muito positivo na defesa dos } \\
\text { interesses dos pais e dos alunos }\end{array}$ & 37 & 71,2 & 15 & 28,8 \\
\hline $\begin{array}{l}\text { 10.2 A AP é o melhor meio de comunicação e cooperação entre os } \\
\text { pais e a escola }\end{array}$ & 33 & 63,5 & 19 & 36,5 \\
\hline $\begin{array}{l}\text { 10.3 A AP tem demonstrado uma atitude de cooperação com a } \\
\text { escola }\end{array}$ & 24 & 46,2 & 28 & 53,8 \\
\hline $\begin{array}{l}\text { 10.4 A AP ajuda a construir e a promover uma imagem positiva da } \\
\text { escola }\end{array}$ & 32 & 61,5 & 20 & 38,5 \\
\hline $\begin{array}{l}\text { 10.5 A AP promove a relação da escola com a comunidade em que } \\
\text { está inserida }\end{array}$ & 22 & 42,3 & 30 & 57,7 \\
\hline $\begin{array}{l}\text { 10.6 A AP promove o reforço da autoridade dos professores junto } \\
\text { dos alunos }\end{array}$ & 48 & 92,3 & 4 & 7,7 \\
\hline $\begin{array}{l}\text { 10.7 A AP facilita o acesso da escola a recursos da comunidade e a } \\
\text { obter subsídios }\end{array}$ & 44 & 84,6 & 8 & 15,4 \\
\hline 10.8 A AP promove a participação de todos os pais & 39 & 75,0 & 13 & 25,0 \\
\hline $\begin{array}{l}\text { 10.9 A AP ajuda os pais que têm mais dificuldade em participar na } \\
\text { escola }\end{array}$ & 50 & 96,2 & 2 & 3,8 \\
\hline 10.10 Outras. (Quais?) & 51 & 98,1 & 1 & 1,9 \\
\hline
\end{tabular}

Como se pode observar no quadro anterior, o fator que mais peso tem para a importância atribuída pelos DTs à AP, é o facto de promover a relação da escola com a comunidade em que está inserida, o que é apontado por $58 \%$ dos inquiridos. Com incidência próxima aparece a atitude de cooperação com a escola, assinalada por $54 \%$ dos sujeitos. A alguma distância, mas ainda assim significativas, são as razões que se prendem com a ajuda que a AP pode dar na construção e promoção de uma imagem positiva da escola e com o facto de ser o melhor meio de comunicação e cooperação entre os pais e a escola, apontadas, cada uma, por cerca de $40 \%$ dos DTs. De forma menos evidente, mas de referir, são os $29 \%$ de inquiridos que consideram importante o papel positivo desempenhado pela AP na defesa dos interesses dos pais e dos alunos.

Em relação aos elementos da amostra que consideram a AP pouco importante, as razões apontadas apresentam-se no quadro seguinte. 


\section{Quadro VI}

Razões da pouca importância da AP

\begin{tabular}{lrrrrr}
\hline & \multicolumn{2}{c}{$\begin{array}{c}\text { Não } \\
\text { assinalado }\end{array}$} & \multicolumn{2}{c}{ Assinalado } \\
\cline { 2 - 6 } & $\mathrm{N}$ & $\%$ & $\mathrm{~N}$ & $\%$ \\
\hline 11.1 A AP apenas representa os interesses de um número & 15 & 68,2 & 7 & 31,8 \\
reduzido de pais & 14 & 63,6 & 8 & 36,4 \\
11.2 A AP não revela uma atitude de cooperação & 14 & 63,6 & 8 & 36,4 \\
11.3 A AP não promove a participação dos pais na escola & 18 & 81,8 & 4 & 18,2 \\
11.4 A AP não se preocupa com os pais que têm mais & 7 & 31,8 & 15 & 68,2 \\
dificuldades em participar & 19 & 86,4 & 3 & 13,6 \\
11.6 A adesão dos pais à AP é muito reduzida & 21 & 95,5 & 1 & 4,5 \\
11.7 É indiferente a existência ou não de AP & & & & \\
11.8 Outras. (Quais?) & & &
\end{tabular}

Através da observação do quadro VI é possível constatar que $68 \%$ dos DTs considera que a pouca importância da AP lhe advém, antes de mais, da muito reduzida adesão dos pais. Outro fator apontado como detrator da imagem da AP é a falta de uma atitude de cooperação e o facto de não promover verdadeiramente a participação dos pais na escola, assinalados por $36 \%$ dos elementos cada. A perceção de que esta associação apenas representa os interesses de um número reduzido de pais também tem um peso significativo na pouca importância atribuída à mesma, sendo apontada por cerca de $32 \%$ dos DTs.

Sumariamente, pode afirmar-se que, embora de forma bem menos significativa do que os encarregados de educação, os DTs têm maioritariamente uma perceção positiva em relação à AP.

Como razões explicativas dessa importância, apontam fatores que correspondem às esperadas virtudes da mesma e aos objetivos a montante da sua criação, a saber: promover a relação da escola com a comunidade em que está inserida, cooperar com a escola, ajudar a promover uma imagem positiva da mesma e a defender os interesses dos pais/encarregados de educação e dos alunos.

Por seu turno, em relação aos posicionamentos apontados por alguns DTs considerando as AP de baixa importância, as suas razões explicativas apontam como fator principal dessa escolha a fraca adesão dos pais, a (falta de) cooperação com a escola, a (não) promoção da participação dos pais na escola e a (não) representação dos interesses de todos os encarregados de educação.

Parece-nos, assim, que os professores consideram que, a funcionar bem, a existência da AP pode dar um substancial contributo para a qualidade de vida da escola e para a promoção da relação escola-família, 
nomeadamente pelo incremento da participação dos pais na vida escolar dos filhos.

De registar o facto de haver uma discrepância entre os dois subgrupos em relação à existência nas suas escolas deste tipo de organização, o que poderá ser justificado com o maior afastamento dos professores em relação às APs, passando um pouco à margem do que à sua existência $\mathrm{e}$ atividade diz respeito.

Consideramos ser esta situação merecedora de uma análise aturada e uma reflexão contextualizada por parte das escolas e das APs, nomeadamente por parte dos seus dirigentes.

\subsection{Análise das entrevistas}

Das entrevistas realizadas a 7 docentes e 4 encarregados de educação, resulta um aprofundamento e uma complementaridade da informação obtida através dos questionários. A análise de conteúdo das mesmas permite verificar que os resultados, no essencial, vão no sentido da confirmação desses resultados.

\section{Perceção dos encarregados de educação}

Importância da A P/Adesão dos EEs; Ser membro da AP/ Participação nas reuniões

Todos os encarregados de educação entrevistados atribuem grande importância à AP. Alguns consideram-na mesmo um elemento fundamental no desenvolvimento da relação entre a escola e a família (EE2 ${ }^{7}$ ) e um ótimo membro para melhorar as coisas (EE5) e para trazer os pais à escola (EE6). Contudo, no dizer dos mesmos, é necessário que funcione ou funcione bem (EE2, EE3, EE4 e EE5). Acrescentam, ainda, seis dos entrevistados que a adesão dos encarregados de educação é muito baixa.

A avaliar pela nossa amostra, a adesão à AP é efetivamente muito fraca, uma vez que apenas dois são membros (EE4 e EE6) e apenas o segundo destes vai às reuniões, uma vez que é Presidente de uma dessas associações, sendo igualmente o único a utilizar esse canal para tratar de assuntos relativos à vida da escola e para resolver problemas.

Fatores que dificultam o bom funcionamento da AP/Características de uma boa AP

\footnotetext{
7 Abreviatura utilizada para identificar o encarregado de educação entrevistado, correspondendo o número à posição da entrevista.
} 
Entre os fatores que dificultam o trabalho das AP, um dos mais apontados prende-se com a falta de comunicação e divulgação (EE1, EE2 e EE4), o que provavelmente contribui para a fraca adesão dos pais, sendo este o outro fator mais considerado (EE1, EE5 e EE6). A falta de tempo dos dirigentes destas associações e a politização das mesmas também são referidas (EE1 e EE2, respetivamente) como constrangimentos ao seu bom funcionamento.

$\mathrm{Na}$ linha dos constrangimentos assinalados, as duas sugestões de mudança nas AP vão no sentido de uma maior divulgação (EE1) e maior participação dos encarregados de educação (EE6).

Quanto às características que deve ter uma AP para que funcione bem, os encarregados de educação têm ideias bem formadas, sendo amplo o leque de exigências. Assim, uma boa AP deve ser abrangente, incluir pais de todos os anos letivos ... transversal (EE3), comunicativa e interventiva... (EE2), ser participativa a todos os níveis, quer com os pais, quer com a direção da escola, ... sugerindo, dando opinião ... trabalho conjunto (EE6) e ainda, que permita a interligação entre alunos, pais e escola (EE7), tente resolver os problemas ... com a escola $e$ participe em atividades extracurriculares (EE4). A imparcialidade ... dos membros que fazem parte ... e das pessoas que estão na sua direção e um maior conhecimento do funcionamento (EE5). Salientamos, no entanto, a referência à possível existência de elementos que estivessem sistematicamente na escola ...(EE1) e o quanto isso seria benéfico para ajudar a resolver os problemas.

\section{Perceção dos DTs}

Importância da AP no desenvolvimento da relação escola-família

Indo ao encontro do apurado nos questionários, todos os elementos da amostra manifestaram uma perceção positiva relativamente ao papel e importância da AP no desenvolvimento da relação escola-família, traduzida por expressões como:

...um papel muito positivo na defesa dos interesses dos pais e dos alunos....pode ser um parceiro muito importante (DT $\left.{ }^{8} 1\right)$; ...assume um papel relevante no desenvolvimento da relação entre a escola e a família... é capaz de promover e defender os interesses dos encarregados de educação e alunos...(DT 2); ...tem um papel determinante na escola (DT 3); ... pode ser um meio de

\footnotetext{
${ }^{8}$ Abreviatura utilizada para identificar o DT de turma entrevistado, correspondendo o número à posição da entrevista.
} 
comunicação muito importante e que faz com que a comunidade tenha uma relação muito estreita... (DT 4).

Contudo, esta perceção corresponde ao plano teórico, sendo acrescentado por alguns dos entrevistados que assim é, se funcionar $e$ bem (DT 4). O DT3 sublinha mesmo que, em relação a essa matéria, $o$ problema é que, na escola...há uma certa desorganização ...

Do exposto se pode confirmar que, na sua maioria, os DTs têm uma posição favorável à existência da $\mathrm{AP}$, revelando, no entanto, algumas reservas em relação à sua eficácia e forma como funcionam efetivamente na prática.

Adesão dos encarregados de educação à AP e fatores que dificultam o seu bom funcionamento

No que respeita à adesão dos encarregados de educação à AP, os DTs entrevistados não têm dúvida, uma vez que todos eles afirmaram ser muito reduzida. Alguns pronunciam-se, inclusive, sobre o lado negativo da situação, lamentando que assim seja, dados os potenciais benefícios que lhes estão associados.

Parece evidente que, tal como acima referido, a fraca adesão à AP, apontada como principal constrangimento a um funcionamento capaz, determina que esta se transforme, sem dúvida, numa "oportunidade perdida" de os encarregados de educação protagonizarem uma intervenção mais organizada, mais positiva e, consequentemente mais adequada (DT1), através da sua participação coletiva.

Esta é uma questão amplamente debatida pelos investigadores nesta área e que tem sido sobejamente trazida à discussão, dadas as consequências em termos de (não)participação dos pais na escola.

\section{REFLEXÃO FINAL}

Da importância vital que uma participação parental positiva e sustentada pode ter no sucesso escolar e educativo das crianças, adolescentes e jovens, parece não existir qualquer margem para dúvidas.

De igual modo, e partindo da premissa de que a construção de uma relação de parceria entre estas duas instâncias educativas só é possível na perspetiva da concertação, da disponibilidade, do diálogo e da cooperação (Mário Pinto, 2009: 27), parece tender a ser generalizada a perceção de que as APs se constituem como espaços privilegiados de construção dessa participação ativa, potenciando os benefícios da mesma 
participação através duma plataforma de atuação coletiva e, por isso, mais forte do ponto de vista da sua assertividade e da sua sustentabilidade.

Assim, é desejável uma evolução positiva por parte dos encarregados de educação, no sentido de uma maior sensibilização face a esta problemática, convertida numa maior adesão ativa às suas associações.

Do mesmo modo, parece-nos de bom-tom que a escola e os seus professores, tornando-se "protagonistas improváveis", se preocupem em colaborar com esta instância educativa, e usufruam, a jusante, das potencialidades que encerra, nomeadamente pelo abrir de portas à comunidade e o acesso a recursos humanos e materiais que tanto podem beneficiar a vida e dinâmicas escolares.

Consideramos um desperdício de oportunidades que em muitas realidades escolares os pais não estejam organizados, uma vez que, a funcionar bem, uma AP poderá, não só contribuir de forma decisiva para a melhoria da participação parental, mas também, atuando numa base de prevenção dos problemas, ajudar a resolver algumas das dificuldades dos professores e da escola, nomeadamente no que respeita ao comportamento dos alunos e ao seu desempenho escolar e educativo.

Com efeito, a escola muito terá a beneficiar se aproveitar todas as oportunidades de estreitar laços com os pais, nomeadamente através da sua associação, promovendo e potenciando atividades que envolvam parcerias.

Como temos vindo a defender, o diagnóstico parece estar feito no que respeita à participação parental, nomeadamente, a participação coletiva através das suas associações. No entanto, a sua efetivação está ainda longe de ser uma realidade generalizada, carecendo de uma verdadeira sensibilização, reflexão conjunta e congregação de vontades e esforços de todos os parceiros educativos, no sentido de perseguir o grande e comum objetivo da melhoria dos resultados escolares e educativos.

Assim, consideramos que à escola, no cumprimento da responsabilidade de tender para um modelo mais aberto aos seus novos desafios, numa perspetiva de melhoria da educação (Miguéns, 2005: 12) e porque, enquanto organização com um avultado capital de conhecimento, está em melhores condições para o fazer, compete a promoção desse envolvimento, facilitando e incentivando a participação dos pais, através de canais diversificados de comunicação e de colaboração que funcionem em regime permanente de parceria e de confiança mútua (id.: 10), designadamente as APs. 


\section{BIBLIOGRAFIA}

Bronfenbrenner, U. (1996). "A ecologia do desenvolvimento humano: experimentos naturais e planejados". Tradução da psicóloga Maria Adriana Veronese. Porto Alegre: Edição Artes Médicas.

Lima, L. C. e Sá, V. (2002). A participação dos pais na governação democrática da escola. In J. Á. Lima (Org.). Pais e professores: um desafio à cooperação, 25-95. Porto: ASA.

Miguéns, M. I. (2005). Nota prévia, Secretário-Geral do Concelho Nacional da Educação. In CNE, Educação e Família, 9-12. Lisboa: CNE.

Sarmento, T. (2009a). As crianças e a cidadania: abordagens participativas em projetos educativos. In Sarmento T. (Org.), Infância, família e comunidade - As crianças como atores sociais, 43-69. Porto: Porto Editora, Lda.

Sarmento, T. (2009 ). Boas práticas escola/família/comunidade. In, CNE, Escola, família, comunidade, 143-147. Lisboa: CNE.

Sarmento, T. $\left(2009_{c}\right)$. As crianças e a cidadania: abordagens participativas em projetos educativos. In Sarmento, T. (org.), Ferreira, F. I., Silva, P., Madeira, R. Infância, Família e Comunidade - As crianças como atores sociais, 43-68. Porto: Porto Editora, Lda.

Sarmento, T. (2005). “(Re)pensar a interacção escola-família”. in Revista Portuguesa de Educação, $n^{\circ} 18:$ pp. 53-75

Silva, P. (1994). Relação escola-família em Portugal: 1974-1994. Duas décadas, um balanço. Inovação, 7, 307-355.

Silva, P. (2002). Escola - Família: tensões e potencialidades de uma relação. In Lima, J. Á.(Org.), Pais e professores, um desafio à cooperação, 97-132. Porto: ASA Editores - S.A.

Silva, P. (2003). Escola - Família, uma Relação Armadilhada. Interculturalidade e Relações de Poder. Porto: Edições Afrontamento.

Sousa, L. (1998). Crianças (con)fundidas entre a Escola e a Família uma perspetiva sistemática para alunos com necessidades educativas especiais. Porto: Porto Editora, LDA. 